\title{
The relationship between ferritin and urate levels and risk of gout
}

\author{
Tahzeeb Fatima', Cushla McKinney', Tanya J. Major ${ }^{1}$, Lisa K. Stamp², Nicola Dalbeth ${ }^{3}$, Cory Iverson ${ }^{4}$,
} Tony R. Merriman ${ }^{1 *}$ (D) and Jeffrey N. Miner ${ }^{5}$

\begin{abstract}
Background: Ferritin positively associates with serum urate and an interventional study suggests that iron has a role in triggering gout flares. The objective of this study was to further explore the relationship between iron/ferritin and urate/gout.

Methods: European (100 cases, 60 controls) and Polynesian (100 cases, 60 controls) New Zealand (NZ) males and 189 US male cases and 60 male controls participated. The 10,727 participants without gout were from the Jackson Heart (JHS; African American = 1260) and NHANES III (European = 5112; African American =4355) studies. Regression analyses were adjusted for age, sex, body mass index and C-reactive protein. To test for a causal relationship between ferritin and urate, bidirectional two-sample Mendelian randomization analysis was performed.

Results: Serum ferritin positively associated with gout in NZ Polynesian (OR (per $10 \mathrm{ng} \mathrm{ml}^{-1}$ increase) $=1.03, p=1.8 \mathrm{E}-03$ ) and US (OR $=1.11, p=7.4 \mathrm{E}-06)$ data sets but not in NZ European $(\mathrm{OR}=1.00, p=0.84)$ data sets. Ferritin positively associated with urate in NZ Polynesian $\left(\beta\left(\mathrm{mg} \mathrm{dl}^{-1}\right)=0.014, p=2.5 \mathrm{E}-04\right), \mathrm{JHS}(\beta=0.009, p=3.2 \mathrm{E}-05)$ and NHANES III (European $\beta=0.007, p=5.1 \mathrm{E}-11$; African American $\beta=0.011, p=2.1 \mathrm{E}-16$ ) data sets but not in NZ European ( $\beta=0.009$, $p=0.31$ ) or US ( $\beta=0.041, p=0.15$ ) gout data sets. Ferritin positively associated with the frequency of gout flares in two of the gout data sets. By Mendelian randomization analysis a one standard deviation unit increase in iron and ferritin was, respectively, associated with $0.11(p=8 \mathrm{E}-04)$ and $0.19 \mathrm{mg} \mathrm{dl}^{-1}(p=2 \mathrm{E}-04)$ increases in serum urate. There was no evidence for a causal effect of urate on iron/ferritin.
\end{abstract}

Conclusions: These data replicate the association of ferritin with serum urate. Increased ferritin levels associated with gout and flare frequency. There was evidence of a causal effect of iron and ferritin on urate.

Keywords: Urate, Gout, Ferritin, Iron, Association, Causal, Mendelian randomization

\section{Background}

Ferritin stores excess iron in a nontoxic form. Urate is a byproduct of purine catabolism in humans. In some hyperuricemic individuals, supersaturation of urate $(>0.41 \mathrm{mmol} /$ L) can result in deposition of monosodium urate (MSU) crystals in the synovium with gout arising due to an innate immune response [1]. Urate acts as a chelator for iron and, in turn, iron can modulate the activity of xanthine oxidase and the production of urate [2]. Indeed, ferritin has been positively associated with serum urate in both the US National Health and Nutrition Examination Survey (NHANES) [3] and the China Health and Nutrition Survey

\footnotetext{
* Correspondence: tony.merriman@otago.ac.nz

${ }^{1}$ Department of Biochemistry, University of Otago, Dunedin, New Zealand Full list of author information is available at the end of the article
}

[4] with elevation in serum urate suggested as an indicator of iron overload [5]. Iron could contribute to gouty inflammation by forming complexes with MSU crystals, stimulating oxidative stress through the generation of reactive oxygen species, and contributing to granulocyte and complement activation [6]. A decrease in gout flares following phlebotomy to attain near iron-deficient levels in hyperuricemic patients [7] is also suggestive of a role in gout.

Food is the primary source of iron, providing heme and nonheme iron through animal and plant sources, respectively. Diet is also a key source of purines. Interestingly, purine-rich foods from an animal-based diet have been associated with increased risk of recurrent gout attacks while purine-rich foods from a plant-based diet are not [8]. These observations, combined with the

(C) The Author(s). 2018 Open Access This article is distributed under the terms of the Creative Commons Attribution 4.0 International License (http://creativecommons.org/licenses/by/4.0/), which permits unrestricted use, distribution, and 
other observational and intervention data [3, 5, 7], are consistent with the hypothesis that iron in purine-rich foods (e.g., red meat) could be a causal factor for gout and flare frequency.

Despite a positive association of iron/ferritin with urate, no data are yet available investigating a possible causal association. The positive association between urate and iron/ferritin could result from unmeasured confounders $[9,10]$. Mendelian randomization can be used to explore the causal association between an exposure and an outcome [11]. This approach exploits random assignment of alleles at conception to disentangle cause and effect in the presence of confounding. Genetic variants that predict an observational exposure are used as unconfounded proxy instruments for the exposure itself to provide evidence of causation for the outcome of interest.

In this study, we first aimed to replicate the observational association of serum ferritin with serum urate and to test for association of serum ferritin with gout and flare frequency. The second aim was to assess a possible causal relationship between iron/ferritin and urate using Mendelian randomization.

\section{Methods}

Biochemical analyses

\section{Study participants}

The NZ participants were recruited during 2006-2014 from community-based settings and primary and secondary health care. The NZ sample set comprised male NZ European (100 cases and 60 controls) and Polynesian (Māori and/or Pacific Island ancestry; 100 cases and 60 controls) individuals. All NZ gout cases were intercritical and had a clinically confirmed diagnosis of gout by the 1977 American Rheumatology Association (ARA) preliminary classification criteria [12]. New Zealand gout cases were not screened for current use of anti-inflammatory therapy. New Zealand control participants without self-reported gout were convenience sampled from the Auckland, Otago and Canterbury regions. The US group comprised a mixture of people of Latino, African American and European ancestry (189 male gout cases and 60 male controls) and serum samples were purchased from Bioreclamation Inc. (New Cassel, NY, USA). All US gout cases had crystal-proven or clinically diagnosed gout, no active acute gout at the time of sample draw, and no nonsteroidal anti-inflammatory drug or colchicine usage within 2 weeks of the sample draw. The US control group comprised sexmatched and ancestrally-matched volunteers. Individuals with a history of liver damage or disease were excluded from the NZ and US case group and US control participants were included if they had never been diagnosed with gout and were not currently taking any nonsteroidal anti-inflammatory drug or colchicine. The Lower South Ethics Committee (OTA/
99/11/098) and the NZ Multi-region Ethics Committee $(\mathrm{MEC} / 05 / 10 / 130)$ granted ethical approval for the $\mathrm{NZ}$ arm. In the US, recruitment of participants for the study had applicable local regulatory requirements (including Institutional Review Board approval). Written informed consent was obtained from all subjects.

Publicly available data from two cohorts were used for serum ferritin versus urate association analyses. A total of 1260 African American individuals were included from the Jackson Heart Study (JHS) [13] via the Database of Genotypes and Phenotypes (approval \#834: The Genetic Basis of Gout). The second data set was The Third National Health and Nutrition Examination Survey (NHANES III) cohort (https://wwwn.cdc.gov/nchs/nhanes/nhanes3/Default.aspx) [14], comprised of 4355 African American and 5112 European individuals. Subjects who self-reported as taking any diuretic or other urate-lowering medication(s), or had kidney disease or gout, or had first-degree relatives with gout were excluded. This categorization was made to assess urate association only in non gout subjects and to minimize bias due to gout or other potential factors affecting urate levels and thus differed from the criteria applied to the previous study that used the same NHANES III data [3]. Also, in contrast to Ghio et al. [3], we analyzed the NHANES III European and African American participants separately and adjusted by C-reactive protein (CRP) levels. Additional file 1: Tables S1 and S2 report the demographic and clinical data for all of the study groups.

\section{Serum biomarker measurements}

Additional file 1 describes the determination of biochemical markers (serum urate, iron, transferrin, ferritin and CRP) for this study.

\section{Statistical analyses}

Differences in the means for intergroup and intragroup comparisons were calculated using an unpaired $t$ test in $\mathrm{R}$ (v3.3.2). Logistic and linear regression analyses were carried out using $\mathrm{R}$ v3.3.2 [15] to test for an association of serum ferritin (explanatory variable) with gout (binary response variable) and urate (continuous response variable), respectively. Individuals with missing data for any variable were excluded. Adjusted odds ratios (ORs) and $\beta$ estimates were obtained by including age (in years), sex, body mass index (BMI) and CRP, and the number of self-reported Polynesian grandparents for the Polynesian sample set, as covariates in the regression models. Ferritin is a marker of inflammation [16] and therefore CRP was included as a covariate in the regression models to control for the possibility that association between ferritin/iron and risk of gout and flare frequency was a consequence of elevated ferritin levels in hyperuricemia [17] and gout [18] per se owing to the increased inflammatory milieu. The urate-producing enzyme xanthine oxidase also releases 
iron from ferritin [19]. Therefore, the average levels of ferritin (and other iron measures) were also compared within the NZ and US gout cases by stratifying the data sets according to the usage of the xanthine oxidase inhibitor allopurinol. Odds ratios for logistic models and $\beta$ estimates for linear regression models were meta-analyzed using the meta package in $\mathrm{R}$ (v3.3.2). A $Q$ statistic was calculated to measure the heterogeneity; if the heterogeneity was significant $(p<0.05)$ the fixed-effect model was replaced with a random-effect model.

\section{Mendelian randomization analysis Selection of instrumental variable}

Mendelian randomization (MR) analysis in this study was based on publicly available summary estimate data for European individuals from the Genetics of Iron Status Consortium $(n=48,978)$ [20] and the Global Urate Genetics Consortium $(n=110,347)$ [21]. The genetic variants were selected as instruments for iron/ ferritin and urate from these GWAS and $p \leq 5 \times 10^{-8}$ was set as a threshold for a variant to be a valid instrument, corresponding to an $F$ statistic of 30 and considered an adequately powered instrument for MR analysis [22]. To minimize pleiotropy, a priori literature searches and eQTL (expression quantitative trait locus) data available online (https://gtexportal.org/home/) and Haploreg v4.1(https://pubs.broadinstitute.org/mammals/hap loreg/haploreg.php) were used to test for association of genetic variants to be included in instruments with expression of genes implicated in iron/ferritin and urate metabolism (as appropriate)-if there was evidence for association then the genetic variant was excluded.

\section{Statistical analyses}

Two-sample Mendelian randomization analysis was performed using the MR-Base (Mendelian Randomization-Base) platform (www.mrbase.org) [23]. The files for exposure instruments were manually uploaded into MR-Base. To eliminate linkage disequilibrium (LD) of $r^{2}>0.6$ between the instruments, the 'LD clumping' command was used. To ensure that the effect estimate of the exposure instrument corresponds to the same allele as the outcome effect, the 'allele harmonization' command was used. The Wald ratio method $[24,25]$ was used to separately calculate the Mendelian randomization estimate for each instrument. With a single instrument, the Wald ratio method is as robust to detect a causal effect as a two-stage least squares method [26, 27]. The effect estimates were combined together in multiple-instrument MR via the inverse-variance weighted method [22], while the Egger-regression method [28] was applied as a sensitivity test for a posteriori adjustment for horizontal pleiotropy within multiple-instrument Mendelian randomization. To determine whether any individual instrument was an outlier, leave-one-out permutation analysis [29] was used as a sensitivity test. A power calculation (for a continuous outcome) was performed using the online calculator for Mendelian randomization studies (https://sb452.shi nyapps.io/power) [30].

\section{Results}

Demographic and biochemical information on the study cohorts is presented in Additional file 1: Tables S1 and S2.

\section{Biochemical observational association analysis Association with serum urate concentration}

Serum ferritin concentration was positively associated with serum urate concentration in nongout African American individuals from the JHS (males $\beta$ per $10 \mathrm{ng} \mathrm{ml}^{-1}$ increase $\left(\mathrm{mg} \mathrm{dl}^{-1}\right)=0.007, p=9.3 \mathrm{E}-03$; females $\beta=0.014, p=1.7 \mathrm{E}-$ 03) and NHANES III (males $\beta=0.006, p=5.1 \mathrm{E}-04$; females $\beta=0.016, p=1.8 \mathrm{E}-15$ ) as well as Europeans (males $\beta=0.004, p=6.6 \mathrm{E}-03$; females $\beta=0.012, p=3.4 \mathrm{E}-10$ ) from the NHANES III study (Table 1). It was interesting to observe the consistently stronger association in females than males (2-fold to 3-fold greater effect size in females; $P_{Q}$ by meta-analysis of males and females was 0.27 in JHS, 1E-04 in NHANES III African American and 1.5E-03 in NHANES III European). A positive association between ferritin and SU was also observed in NZ Polynesian ( $\beta$ $=0.014, p=2.5 \mathrm{E}-04$ ) individuals, but not in NZ European $(\beta=0.009, p=0.31)$ or US $(\beta=0.041, p=0.15)$ individuals from the gout control sample sets (Table 1 ).

\section{Association with gout}

The average levels of ferritin were elevated in both NZ Polynesian $(p=2.3 \mathrm{E}-04)$ and US $(p=6.6 \mathrm{E}-17)$ gout cases compared to controls, but not between NZ European gout cases and controls $(p=0.21)$ (Table 2). An increase in serum ferritin of $10 \mathrm{ng} \mathrm{ml}^{-1}$ was associated with an increased risk of developing gout in NZ Polynesian (OR $(\mathrm{CI})=1.03$ (1.01; 1.05), $p=1.8 \mathrm{E}-03)$ and US (OR (CI) $=1.11$ (1.07; 1.17), $p=7.4 \mathrm{E}-06$ ) individuals. However, ferritin was not associated with increased risk of gout in the NZ European sample set $(\mathrm{OR}(\mathrm{CI})=1.00(0.97 ; 1.02), p=0.84)$ (Table 2). Exclusion of gout patients on allopurinol treatment from the US sample set did not influence the association of ferritin levels with gout $(\mathrm{OR}(\mathrm{CI})=1.11(1.06 ; 1.16)$, $p=2.4 \mathrm{E}-05)$.

\section{Association of ferritin with flare frequency}

We also tested for an association of serum ferritin, CRP and serum urate with self-reported frequency of gout flares (per year). Each $10 \mathrm{ng} \mathrm{m}^{-1}$ increase in ferritin was associated with an increased frequency of gout flares in the US ( $\beta=0.02$ flares/year, $p=2 \mathrm{E}-03)$ and NZ European $(\beta=0.09, p=0.04)$ individuals but not in NZ Polynesian $(\beta=-0.11, p=0.14)$ individuals. $C$-reactive protein and 
Table 1 Association of ferritin (per $10 \mathrm{ng} \mathrm{ml}^{-1}$ increment) with serum urate $\left(\mathrm{mg} \mathrm{dl}^{-1}\right)$

\begin{tabular}{llllll}
\hline Population & $n^{\mathrm{a}}$ & $\beta(95 \% \mathrm{Cl})^{\mathrm{b}}$ & $p^{\mathrm{b}}$ & $\beta(95 \% \mathrm{Cl})^{\mathrm{c}}$ & $p^{\mathrm{c}}$ \\
\hline NZ European & 60 & $0.011(-0.006 ; 0.027)$ & 0.24 & $0.009(-0.009 ; 0.027)$ & 0.31 \\
NZ Polynesian & 60 & $0.015(0.007 ; 0.023)$ & $1.4 \mathrm{E}-04$ & $0.014(0.007 ; 0.022)$ & $0.5 \mathrm{E}-04$ \\
US & 60 & $0.048(-0.006 ; 0.102)$ & 0.079 & $0.041(-0.015 ; 0.097)$ & 0.15 \\
JHS (males) & 567 & $0.008(0.002 ; 0.014)$ & $9.6 \mathrm{E}-03$ & $0.007(0.002 ; 0.014)$ & $9.3 \mathrm{E}-03$ \\
JHS (females) & 693 & $0.023(0.015 ; 0.032)$ & $1.6 \mathrm{E}-07$ & $0.014(0.005 ; 0.022)$ & $1.7 \mathrm{E}-03$ \\
JHS (combined) & 1260 & $0.027(0.023 ; 0.033)$ & $1.8 \mathrm{E}-27$ & $0.009(0.005 ; 0.014)$ & $3.2 \mathrm{E}-05$ \\
NHANES III African American (males) & 1925 & $0.010(0.007 ; 0.014)$ & $7.2 \mathrm{E}-09$ & $0.006(0.003 ; 0.009)$ & $5.1 \mathrm{E}-04$ \\
NHANES III African American (females) & 2430 & $0.028(0.027 ; 0.032)$ & $1.3 \mathrm{E}-42$ & $0.016(0.012 ; 0.020)$ & $1.8 \mathrm{E}-15$ \\
NHANES III African American (combined) & 4355 & $0.029(0.026 ; 0.031)$ & $2.0 \mathrm{E}-97$ & $0.011(0.008 ; 0.013)$ & $2.1 \mathrm{E}-16$ \\
NHANES III European (males) & 2460 & $0.006(0.003 ; 0.009)$ & $1.0 \mathrm{E}-04$ & $0.004(0.001 ; 0.007)$ & $6.6 \mathrm{E}-03$ \\
NHANES III European (females) & 2652 & $0.019(0.015 ; 0.023)$ & $1.3 \mathrm{E}-22$ & $0.012(0.008 ; 0.015)$ & $3.4 \mathrm{E}-10$ \\
NHANES III European (combined) & 5112 & $0.025(0.023 ; 0.028)$ & $6.9 \mathrm{E}-84$ & $0.007(0.005 ; 0.009)$ & $5.1 \mathrm{E}-11$ \\
Meta-analyzed data & 10,907 & $0.025(0.021 ; 0.028)$ & $9.3 \mathrm{E}-34$ & $0.009(0.007 ; 0.011)$ & $3.9 \mathrm{E}-32$ \\
\hline Beta values repres &
\end{tabular}

Beta values represent change in serum urate in $\mathrm{mg} \mathrm{dl}^{-1}$ per $10 \mathrm{ng} \mathrm{ml}^{-1}$ increase in concentration of serum ferritin

Cl confidence interval, NZ New Zealand, US United States, JHS Jackson Heart Study, NHANES National Health and Nutrition Examination Survey

${ }^{a}$ Number of nongout (control) individuals

bunadjusted

'Adjusted for age, body mass index, C-reactive protein and number of self-reported Polynesian grandparents in the NZ Polynesian analyses. Combined analyses are additionally adjusted for sex

urate concentrations were not associated with frequency of gout flares in all three data sets (Table 3).

\section{Association of ferritin levels with allopurinol use}

Significantly increased serum ferritin levels were observed among participants with gout who reported taking allopurinol in the NZ Polynesian $(p=0.005)$ and US $(p=0.02)$ sample sets; however, the average levels of ferritin were not significantly different in the NZ European sample set when the same stratification was done $(p=0.47)$ (Table 4$)$.

\section{Analysis with log-transformed ferritin}

The ferritin distribution deviated from normality for all study groups (Additional file 1: Figure S1, S2), therefore the data were $\log$ transformed. Results for the log-transformed (normalized) data are presented in Additional file 1: Tables S3-S5. The results were similar to those from the untransformed data.

\section{Mendelian randomization analysis}

The Mendelian randomization analysis had $100 \%$ power to detect a causal effect (change in outcome in SD units per SD change in exposure) of 0.1 at $p<0.05$. The two GWASs selected for two-sample MR (84,978 for iron measures [20] and 110,347 for serum urate [21]) had an overlap of 20,160 individuals; this overlap is considered sufficiently low to avoid any potential bias in Mendelian randomization estimates [31].

Additional file 1: Table S6 provides the list of genetic variants evaluated as instrumental variables for iron $(n=3)$, ferritin $(n=5)$ and urate $(n=3)$. Details of selection of these instruments, along with approaches to minimize pleiotropy, are outlined in Additional file 1 and Additional file 1: Figure S3.

Table 2 Comparison of average values of serum ferritin $\left(\mathrm{ng} \mathrm{ml}^{-1}\right)$ in gout case-control groups and the association with gout

\begin{tabular}{|c|c|c|c|c|c|c|}
\hline \multirow[t]{2}{*}{ Population } & \multicolumn{2}{|c|}{ Comparison of average } & \multicolumn{4}{|c|}{ Association analysis } \\
\hline & $p$ & $\overline{(95 \% \mathrm{Cl})_{\text {for difference }}}$ & $\mathrm{OR}(95 \% \mathrm{Cl})^{\mathrm{a}}$ & $p^{\mathrm{a}}$ & OR $(95 \% \mathrm{Cl})^{\mathrm{b}}$ & $p^{b}$ \\
\hline NZ European & 0.21 & $(-97.46 ; 22.02)$ & $1.01(0.99 ; 1.03)$ & 0.22 & $1.00(0.97 ; 1.02)$ & 0.84 \\
\hline NZ Polynesian & $2.3 \mathrm{E}-04$ & $(-211.88 ;-66.31)$ & $1.03(1.01 ; 1.05)$ & 1.7E-03 & $1.03(1.01 ; 1.06)$ & $1.8 \mathrm{E}-03$ \\
\hline US & $6.6 \mathrm{E}-17$ & $(-167.19 ;-107.16)$ & $1.25(1.07 ; 1.17)$ & $1.5 \mathrm{E}-06$ & $1.11(1.07 ; 1.17)$ & 7.4E-06 \\
\hline US no allopurinol & $6.6 \mathrm{E}-17$ & $(-167.19 ;-107.16)$ & $1.11(1.07 ; 1.16)$ & $4.5 \mathrm{E}-06$ & $1.11(1.06 ; 1.16)$ & 2.4E-05 \\
\hline Meta-analysis ${ }^{c}$ & - & - & $1.04(1.01 ; 1.08)$ & 0.02 & $1.04(0.99 ; 1.09)$ & 0.09 \\
\hline
\end{tabular}

All OR values represent change in risk per $10 \mathrm{ng} \mathrm{m}^{-1}$ increase in serum ferritin

Cl confidence interval, OR odds ratio, NZ New Zealand, US United States

anadjusted

${ }^{\mathrm{b}}$ Adjusted for age, body mass index, C-reactive protein and number of self-reported Polynesian grandparents in the NZ Polynesian analyses

'Only sample sets not stratified for allopurinol exposure were included in the meta-analysis 
Table 3 Association of serum ferritin, CRP and serum urate with gout flares/year

\begin{tabular}{|c|c|c|c|c|c|c|c|c|}
\hline \multirow[t]{2}{*}{ Population } & \multicolumn{4}{|c|}{ Ferritin $\left(\mathrm{ng} \mathrm{ml^{-1 }}\right)$} & \multicolumn{2}{|c|}{ C-reactive protein $\left(\mathrm{mg} \mathrm{dl}^{-1}\right)$} & \multicolumn{2}{|c|}{ Serum urate $\left(m g \mathrm{dl}^{-1}\right)$} \\
\hline & $\overline{\beta(95 \% C l)^{a}}$ & $p^{\mathrm{a}}$ & $\beta(95 \% \mathrm{Cl})^{\mathrm{b}}$ & $p^{\mathrm{b}}$ & $\beta(95 \% C l)^{a}$ & $p^{a}$ & $\overline{\beta(95 \% C l)^{a}}$ & $p^{a}$ \\
\hline NZ European & $\begin{array}{l}0.09 \\
(0.003 ; 0.17)\end{array}$ & 0.042 & $\begin{array}{l}0.069 \\
(-0.01 ; 0.14)\end{array}$ & 0.067 & $\begin{array}{l}1.75 \\
(-3.85 ; 7.37)\end{array}$ & 0.54 & $\begin{array}{l}-0.61 \\
(-1.48 ; 0.25)\end{array}$ & 0.16 \\
\hline NZ Polynesian & $\begin{array}{l}-0.11 \\
(-0.24 ; 0.03)\end{array}$ & 0.14 & $\begin{array}{l}-0.091 \\
(-0.22 ; 0.03)\end{array}$ & 0.15 & $\begin{array}{l}-9.95 \\
(-23.75 ; 3.84)\end{array}$ & 0.16 & $\begin{array}{l}-1.59 \\
(-3.88 ; 0.71)\end{array}$ & 0.17 \\
\hline US & $\begin{array}{l}0.02 \\
(0.01 ; 0.04)\end{array}$ & 0.002 & $\begin{array}{l}0.018 \\
(0.001 ; 0.04)\end{array}$ & 0.043 & $\begin{array}{l}0.10 \\
(-0.13 ; 0.35)\end{array}$ & 0.38 & $\begin{array}{l}0.13 \\
(-0.04 ; 0.30)\end{array}$ & 0.13 \\
\hline
\end{tabular}

Values represent change in the annual frequency of flares per $10 \mathrm{ng} \mathrm{ml}^{-1}$ increase in serum ferritin. Levels of urate are at the time of subject recruitment CRP C-reactive protein, Cl confidence interval, NZ New Zealand, US United States

${ }^{a}$ Adjusted for age, body mass index and number of self-reported Polynesian grandparents in the NZ Polynesian analyses

${ }^{b}$ Additionally adjusted for allopurinol usage

\section{Iron biomarkers as exposures for urate as outcome}

The strongest signal for iron and ferritin at HFE rs 1800562 (allele A) in the exposure data was found to causally increase urate levels in Europeans (iron $\beta=0.11 \mathrm{mg} \mathrm{dl}^{-1}$ increase in serum urate per standard deviation unit increase in iron, $p=0.0008$; ferritin $\beta=0.19, p=0.0002$ ) (Table 5). A causal effect of ferritin levels on urate levels was also observed when $A B O$ rs651007 (allele T) was used as a single instrument in the Mendelian randomization model $(\beta=0.32, p=0.02)$ (Table 5). However multiple-instrument Mendelian randomization using the inverse-variance weighted method did not indicate any causal effect of iron $\left(\beta=0.056, \quad p=0.15, \quad P_{Q}=0.18\right)$ or ferritin $(\beta=0.089$, $p=0.17, P_{Q}=0.06$ ) on urate (Table 5). The nonsignificant effect remained consistent after a posteriori adjustment for horizontal pleiotropy, with effects across the variants showing heterogeneity, via MR-Egger for both iron $(\beta=0.064$, $\left.p=0.61, P_{Q}=0.01\right)$ and ferritin $\left(\beta=0.16, p=0.32, P_{Q}=0.01\right)$ (Table 5). MR-Egger did not indicate high pleiotropy for an effect on urate using all three instruments for iron $\left(p_{\text {intercept }}=0.95\right)$ and five instruments for ferritin $\left(p_{\text {intercept }}=0.58\right) \quad($ Table 5$)$. However, leave-one-out sensitivity analysis indicated TMPRSS6 rs855791 and SLC40A1 rs12693541 to be potential outliers driving a noncausal observed effect of iron and ferritin on urate, respectively (Table 6). Leaving these two variants out in a subsequent combined inverse-variance weighted analysis demonstrated iron $(\beta=0.11, p=1.96 \mathrm{E}-04)$ and ferritin ( $\beta=0.14, p=0.03$ ) to causally increase urate levels in Europeans (Table 6).

\section{Urate as exposure for iron biomarkers as outcome}

None of the urate instruments (SLC2A9 rs12498742, SLC16A9 rs1171614 and SLC22A12 rs478607) indicated causality for serum urate levels on iron and ferritin levels when tested individually (Additional file 1: Table S7). The noncausal relationship remained consistent when analyzed using multiple-instrument inverse-variance weighting and a posteriori adjustment for horizontal pleiotropy using MR-Egger (Additional file 1: Table S7). By leave-one-out analysis, none of the urate instruments was an outlier for a causal effect on iron or ferritin (Additional file 1: Table S8).

\section{Discussion}

We extended the previously reported associations of serum ferritin with serum urate $[3,4]$ using adjustment by CRP to exclude the possibility that the relationship is a consequence of the association of ferritin with inflammatory states, particularly since there is evidence that serum urate levels drop in acute inflammation in hospitalized patients [32]. The association of serum ferritin with serum urate has now been reported in European, Chinese, African American, and NZ Māori and Pacific (Polynesian) sample sets. We associated increased serum ferritin with the risk of gout and gout flares, although

Table 4 Self-reported allopurinol use and iron profile comparison in gout patients

\begin{tabular}{lllll}
\hline Population/marker & No allopurinol & Allopurinol & $p$ & $(95 \% \mathrm{Cl})_{\text {for difference }}$ \\
\hline NZ European $(n)$ & 23 & 66 & - & $(-10.661 ; 14.258)$ \\
Serum iron $\left(\mu \mathrm{mol} \mathrm{L}^{-1}\right)$ & 100.44 & 98.65 & 0.77 & $(-115.787 ; 54.597)$ \\
Serum ferritin $\left(\mathrm{ng} \mathrm{ml}^{-1}\right)$ & 253.71 & 284.31 & 0.48 & $(-4.592 ; 16.816)$ \\
NZ Polynesian $(n)$ & 22 & 74 & & 0.26 \\
Serum iron $\left(\mu \mathrm{mol} \mathrm{L}^{-1}\right)$ & 91.21 & 85.08 & 0.005 & $(-204.466 ;-36.548)$ \\
Serum ferritin $\left(\mathrm{ng} \mathrm{ml}^{-1}\right)$ & 373.81 & 494.32 & & $(-164.816 ; 14.451)$ \\
US $(n)$ & 155 & 34 & 0.02 & \\
Serum ferritin $\left(\mathrm{ng} \mathrm{ml}^{-1}\right)$ & 158.57 & 248.21 & & \\
\hline
\end{tabular}

Cl confidence interval, NZ New Zealand, US United States 
Table 5 Association between iron/ferritin and urate using two-sample Mendelian randomization

\begin{tabular}{|c|c|c|c|c|c|c|c|c|c|c|c|}
\hline \multirow{2}{*}{$\begin{array}{l}\text { MR } \\
\text { analysis }\end{array}$} & \multicolumn{2}{|l|}{ Phenotype } & \multirow{2}{*}{$\begin{array}{l}\text { Gene/ } \\
\text { locus }\end{array}$} & \multirow{2}{*}{$\begin{array}{l}\text { Genetic } \\
\text { variant }\end{array}$} & \multirow[t]{2}{*}{ estimate } & \multirow[t]{2}{*}{ SE } & \multirow[t]{2}{*}{$(95 \% \mathrm{Cl})$} & \multirow[t]{2}{*}{ p-causal } & \multirow[t]{2}{*}{$Q-p$} & \multicolumn{2}{|c|}{ MR Egger_HP } \\
\hline & Exposure & Outcome & & & & & & & & intercept & $p$ value \\
\hline Wald ratio & Iron & Urate & TF & rs1525892 & 0.127 & 0.076 & $(-0.02 ; 0.28)$ & 0.093 & - & - & - \\
\hline- & Iron & Urate & HFE & rs 1800562 & 0.107 & 0.032 & $(0.04 ; 0.17)$ & 0.0008 & - & - & - \\
\hline- & Iron & Urate & TMPRSS6 & rs855791 & -0.001 & 0.031 & $(-0.06 ; 0.06)$ & 0.99 & - & - & - \\
\hline IVW & Iron & Urate & - & All & 0.056 & 0.039 & $(-0.02 ; 0.13)$ & 0.15 & 0.179 & - & - \\
\hline MR Egger & Iron & Urate & - & All & 0.064 & 0.109 & $(-0.15 ; 0.28)$ & 0.61 & 0.011 & -0.0016 & 0.95 \\
\hline Wald ratio & Log ferritin & Urate & SLC40A1 & rs 12693541 & -0.068 & 0.076 & $(-0.22 ; 0.08)$ & 0.37 & - & - & - \\
\hline- & Log ferritin & Urate & HFE & rs 1800562 & 0.190 & 0.057 & $(0.08 ; 0.30)$ & 0.0002 & - & - & - \\
\hline- & Log ferritin & Urate & TMPRSS6 & rs2413450 & 0.011 & 0.106 & $(-0.20 ; 0.22)$ & 0.92 & - & - & - \\
\hline- & Log ferritin & Urate & TEX14 & rs411988 & -0.048 & 0.123 & $(-0.29 ; 0.19)$ & 0.70 & - & - & - \\
\hline- & Log ferritin & Urate & $A B O$ & rs651007 & 0.320 & 0.140 & $(0.05 ; 0.59)$ & 0.022 & - & - & - \\
\hline IVW & Log ferritin & Urate & - & All & 0.089 & 0.066 & $(-0.04 ; 0.22)$ & 0.18 & 0.063 & - & - \\
\hline MR Egger & Log ferritin & Urate & - & All & 0.160 & 0.134 & $(-0.10 ; 0.42)$ & 0.32 & 0.014 & -0.0067 & 0.58 \\
\hline
\end{tabular}

All beta estimates presented as an effect of per standard deviation unit change in iron and ferritin on change in urate (mg $\mathrm{dl}^{-1}$ )

$M R$ Mendelian randomization, SE standard error, $C l$ confidence interval, $\mathrm{p}$-causal $p$ value using MR analysis, Q-p Cochran's heterogeneity test showing $p$ value for heterogeneity, MR Egger_HP Egger test for horizontal pleiotropy, IVW meta-analysis using inverse-variance method, MR Egger Mendelian randomization using

Egger regression

for both relationships an association was observed in only two of the three data sets used. Given that allopurinol exposure raises ferritin levels and given the limited number of gout patients not exposed to allopurinol available to us, we cannot conclude that the gout-ferritin association is independent of allopurinol exposure. Mendelian randomization single instrument analysis (Table 5) and multiple instrument leave-one-out analysis (Table 6) provided evidence for a causal role of iron and ferritin in increasing urate levels in Europeans. In single instrument analysis, HFE rs 1800562 provided evidence of causality. In multiple instrument 'leave-one-out' sensitivity analysis, excluding two variants (TMPRSS6 rs855791 and SLC40A1 rs12693541) also provided evidence of causality. These variants may obscure a causal effect because they mediate an unidentified link between urate and ferritin metabolism.

Metal ions can potentially cause oxidative stress when bound to storage or transport proteins [33] and urate is a well-known antioxidant in humans, by scavenging oxygen radicals, singlet oxygen and oxo-heme oxidants [34-36]. Thus it has been proposed that urate could reduce iron-catalyzed oxidative stress by acting as a metal chelator [37]. Xanthine oxidase acts as the sole enzymatic source of urate in humans and exposure to iron may enhance its activity $[2,38,39]$. This may explain a causal

Table 6 Leave-one-out sensitivity analysis for association between iron/ferritin and urate using inverse-variance weighted twosample Mendelian randomization

\begin{tabular}{|c|c|c|c|c|c|}
\hline \multicolumn{2}{|l|}{ Phenotype } & \multirow{2}{*}{$\begin{array}{l}\text { Instrumental variant } \\
\text { excluded from IWW } \\
\text { analysis }\end{array}$} & \multirow[t]{2}{*}{$\beta$ estimate } & \multirow[t]{2}{*}{$(95 \% \mathrm{Cl})$} & \multirow[t]{2}{*}{ p-causa } \\
\hline Exposure & Outcome & & & & \\
\hline Iron & Urate & TF rs1525892 & 0.050 & $(-0.06 ; 0.16)$ & 0.35 \\
\hline Iron & Urate & HFE rs 1800562 & 0.017 & $(-0.07 ; 0.10)$ & 0.70 \\
\hline Iron & Urate & TMPRSS6 rs855791 & 0.110 & $(0.05 ; 0.17)$ & 2.0E-04 \\
\hline Iron & Urate & All & 0.050 & $(-0.02 ; 0.13)$ & 0.15 \\
\hline Log ferritin & Urate & SLC40A1 rs 12693541 & 0.141 & $(0.02 ; 0.27)$ & 0.027 \\
\hline Log ferritin & Urate & HFE rs 1800562 & 0.007 & $(-0.14 ; 0.15)$ & 0.93 \\
\hline Log ferritin & Urate & TMPRSS6 rs2413450 & 0.101 & $(-0.05 ; 0.26)$ & 0.20 \\
\hline Log ferritin & Urate & TEX14 rs411988 & 0.103 & $(-0.04 ; 0.25)$ & 0.17 \\
\hline Log ferritin & Urate & $A B O$ rs651007 & 0.070 & $(-0.06 ; 0.20)$ & 0.30 \\
\hline Log ferritin & Urate & All & 0.089 & $(-0.04 ; 0.22)$ & 0.18 \\
\hline
\end{tabular}

All beta estimates presented as an effect of per standard deviation unit change in iron and ferritin on change in urate $\left(\mathrm{mg} \mathrm{dl}^{-1}\right.$ )

IVW meta-analysis using inverse-variance method, $\mathrm{Cl}$ confidence interval, $\mathrm{p}$-causal $p$ value using IVW meta-analysis, HFE human hemochromatosis protein, TMPRSS6 transmembrane protease serine-6, ABO alpha 1-3-N-acetylgalactosaminyltransferase 
effect of iron on serum urate levels. A Mendelian randomization analysis demonstrated causality of iron/ ferritin on renal function with increased levels being protective [40]. Given that reduced renal function is causal of hyperuricemia, it is unlikely that our Mendelian randomization data, supporting a causal role for iron/ferritin increasing serum urate levels, is mediated via an effect on kidney function. An increase in urate in both rodents [41, 42] and humans [43] in response to acute exposure to iron also supports a direct link between levels of iron and urate. Elevated serum urate is sometimes used as a cue to screen for hemochromatosis [5]. Our study, however, did not provide any evidence supporting a causal effect of urate on iron/ferritin levels.

We found a positive correlation between the number of gout flares and ferritin. Iron deposits have been reported to be consistently present in the synovial membrane of people with rheumatoid arthritis but not those with other joint pathologies [44]. Some rodent studies have also demonstrated an improvement in joint-related inflammation following the removal of iron by chelation treatment $[45,46]$. Maintenance of near iron deficiency by depleting the levels via phlebotomy in people with gout induces either complete or marked reduction in incidence and severity of gout flares in humans [7].

Iron-rich foods are top triggers for gout flares: $62.5 \%$ people with gout reporting seafood/fish, 35.2\% red meat [47]. There is a positive correlation between the consumption of red meat and incident gout risk in a study of 28,990 men [48], and another study in 47,150 men associated the consumption of meat and seafood, but not purine-rich vegetables, with an increased risk of incident gout [49]. A Turkish retrospective study indicated that higher consumption of total meat (including fish) acts as a precipitating factor for gout flares [50]. Also, purines from animal-based, but not plant-based, food have been associated with increased risk of recurrent gout attacks [8]. In line with these findings there is an association of increased consumption of red meat with hyperuricemia in NHANES III [51]. It is possible that, additional to purines, the iron content of animal-based foods contributes to the risk of gout and flares.

There was elevation of serum ferritin levels in individuals on allopurinol treatment. This is of interest as xanthine oxidase is involved in the release of iron from ferritin and facilitating cellular stress through the production of hydroxyl radicals [19]. Use of allopurinol as a xanthine oxidase inhibitor has been attributed to an increased iron overload in rodent liver cells and elevated serum iron in patients with secondary gout [52]. Although a possible influence of allopurinol in iron metabolism in human is unclear, our results are consistent with previous reports [53, 54], namely that our data imply higher serum ferritin levels in gout patients on allopurinol therapy. Confirming the possible effect of allopurinol on iron metabolism in gout patients, using cohorts that are matched for clinical features of gout, could assist decision-making in treatment options for patients with a risk of iron overload. It is interesting to observe that a possible consequence of allopurinol exposure in gout could be an increase in serum urate levels via a possible causal effect of increased ferritin levels, although any increase would be considerably smaller than the decrease exacted by inhibition of xanthine oxidase by allopurinol.

There are several limitations to our study. Firstly, the gout cases were ascertained differently between the NZ and US cohorts (by clinical diagnosis only and by a combination of clinical diagnosis and crystal-proven gout, respectively). Furthermore, the NZ gout cases were not screened for current exposure to anti-inflammatory medication, a potential confounder. Secondly, only a limited number of possible confounders were adjusted for in the serum ferritin versus serum urate/gout/flares analyses. Other possible confounders could be alcohol (and other dietary exposures), liver steatosis and diabetes. The primary reason for using a limited set of confounders was the limited data available in the US gout sample set. Therefore, our observational epidemiological data can only support the observation that increased ferritin levels associate with serum urate levels, the risk of gout and the number of self-reported flares and cannot be used to claim that this association is independent of known confounders. Certainly, our data support a role for allopurinol in raising ferritin levels (Table 4). We do note, however, that the Mendelian randomization analysis supported a causal role for increased serum ferritin levels in increasing serum urate levels. Thirdly, self-report of gout flares can be regarded as an inaccurate method of flare frequency ascertainment, although it is the only practical way of collecting these data in large cohorts for epidemiological studies. However, it has been reported that, compared to the gold standard of physician assessment of flare, self-reported flares have a high sensitivity of 91\% [55]. Finally, the Mendelian randomization data are unreplicated and only performed using cohorts of European ancestry. Currently it is not possible to replicate owing to the unavailability of suitable independent sample sets.

The consistency of our observational findings with previously reported experimental and clinical intervention studies and the positive causal association via Mendelian randomization analysis, albeit unreplicated, support the argument that there is a causal relationship between serum iron/ferritin and urate. This could have clinical implications with respect to causing gout. (We are unaware of any studies investigating links between hemochromatosis and gout.) Furthermore, our data 
support investigation of the possibility of an iron-rich diet as a trigger for gout flares that may ultimately improve flare avoidance advice given to people with gout.

\section{Conclusions}

This study further confirmed the observational relationship between increased serum ferritin and iron levels and serum urate levels. We provide the first evidence for positive association of serum ferritin levels with the risk of gout and with the frequency of gout flares. By Mendelian randomization there was evidence for a causal relationship for ferritin and iron in increasing urate levels, but not for urate increasing ferritin and iron levels. Clinically, our data suggest that consideration of avoidance of iron-rich foods could improve flare avoidance advice given to people with gout.

\section{Additional file}

Additional file 1: Supplemental methods, Tables S1.-S8. and

Figures S1.-S3. (DOCX $578 \mathrm{~kb}$ )

\begin{abstract}
Abbreviations
ABO: Alpha 1-3-N-acetylgalactosaminyltransferase; ARA: American Rheumatology Association; BMl: Body mass index; Cl: Confidence interval; CRP: C-reactive protein; eQTL: Expression quantitative trait locus; GWAS: Genome-wide association study; HFE: Human hemochromatosis protein; JHS: Jackson Heart Study; LD: Linkage disequilibrium; MR: Mendelian randomization; MSU: Monosodium urate; NHANES: National Health and Nutrition Examination Survey; NY: New York; NZ: New Zealand; OR: Odds ratio; SD: Standard deviation; SLC: Solute carrier; TMPRSS6: Transmembrane protease serine-6; US: United States
\end{abstract}

\section{Acknowledgements}

The Health Research Council of New Zealand, Arthritis New Zealand, New Zealand Lottery Health and the University of Otago supported this work. The authors would like to thank Jill Drake (Canterbury District Health Board), Roddi Laurence, Chris Franklin, Meaghen House, Jordyn Allen (all University of Auckland) and Gabrielle Sexton (University of Otago) for recruitment. The authors would also like to thank Vivienne Trethowen from Southern Community Laboratory, Dunedin Hospital, New Zealand for iron profile measurements for the New Zealand sample sets. The Jackson Heart Study is supported and conducted in collaboration with Jackson State University (HHSN268201300049C and HHSN268201300050C), Tougaloo College (HHSN268201300048C) and the University of Mississippi Medical Center (HHSN268201300046C and HHSN268201300047C) with contracts from the National Heart, Lung, and Blood Institute (NHLBI) and the National Institute for Minority Health and Health Disparities (NIMHD). The authors thank the participants and data collection staff of the Jackson Heart Study. The views expressed in this manuscript are those of the authors and do not necessarily represent the views of the National Heart, Lung, and Blood Institute; the National Institutes of Health; or the US Department of Health and Human Senvices.

\section{Funding}

The study was funded by the Health Research Council of NZ and Ardea Biosciences. Neither of the funders had influence over the interpretation of results and writing of the manuscript.

\section{Availability of data and materials}

Individual-level blood biochemical data on the NZ and US gout data sets may be available on request, with a clear statement of purpose.

\section{Authors' contributions}

TF and TRM helped to design the study, oversee its execution and write the manuscript. ND and LKS helped to provide clinical data and write the manuscript. CM and TJM helped to analyze and/or interpret data and write the manuscript. Cl and JNM helped to generate data and write the manuscript. All authors read and approved the final manuscript.

Ethics approval and consent to participate

The Lower South Ethics Committee (OTA/99/11/098) and the NZ Multi-region Ethics Committee (MEC/05/10/130) granted ethical approval for the NZ arm. In the US, recruitment of participants for the study had applicable local regulatory requirements (including Institutional Review Board approval). Written informed consent was obtained from all subjects.

\section{Consent for publication}

Not applicable.

\section{Competing interests}

The authors declare that they have no competing interests.

\section{Publisher's Note}

Springer Nature remains neutral with regard to jurisdictional claims in published maps and institutional affiliations.

\section{Author details}

${ }^{1}$ Department of Biochemistry, University of Otago, Dunedin, New Zealand. ${ }^{2}$ Department of Medicine, University of Otago, Christchurch, New Zealand. ${ }^{3}$ Department of Medicine, University of Auckland, Auckland, New Zealand. ${ }^{4}$ Medical Scientific Affairs, Ironwood Pharmaceuticals, Cambridge, MA, USA. ${ }^{5}$ Biology, Ardea Biosciences, Inc., San Diego, CA, USA.

Received: 25 February 2018 Accepted: 12 July 2018

Published online: 15 August 2018

References

1. Dalbeth N, Merriman TR, Stamp LK. Gout. Lancet. 2016;388:2039-52.

2. Ghio AJ, Kennedy TP, Stonehuerner J, Carter JD, Skinner KA, Parks DA, Hoidal JR. Iron regulates xanthine oxidase activity in the lung. Am J Physiol Lung Cell Mol Physiol. 2002;283:L563-72.

3. Ghio AJ, Ford ES, Kennedy TP, Hoidal JR. The association between serum ferritin and uric acid in humans. Free Rad Res. 2005:39:337-42.

4. Li X, He T, Yu K, Lu Q, Alkasir R, Guo G, Xue Y. Markers of iron status are associated with risk of hyperuricemia among Chinese adults: nationwide population-based study. Nutrients. 2018;10:E191.

5. Mainous AG, Knoll ME, Everett CJ, Matheson EM, Hulihan MM, Grant AM. Uric acid as a potential cue to screen for iron overload. J Am Board Fam Med. 2011;24:415-21.

6. Ghio AJ, Kennedy TP, Rao G, Cooke CL, Miller MJ, Hoidal JR. Complexation of iron cation by sodium urate crystals and gouty inflammation. Arch Biochem Biophys. 1994:313:215-21.

7. Facchini FS. Near-iron deficiency-induced remission of gouty arthritis. Rheumatol. 2003;42:1550-5.

8. Zhang Y, Chen C, Choi H, Chaisson C, Hunter D, Niu J, Neogi T. Purine-rich foods intake and recurrent gout attacks. Ann Rheum Dis. 2012;71:1448-52.

9. Hayden JA, van der Windt DA, Cartwright JL, Cote P, Bombardier C. Assessing bias in studies of prognostic factors. Ann Intern Med. 2013;158:280-6.

10. Shrank WH, Patrick AR, Brookhart MA. Healthy user and related biases in observational studies of preventive interventions: a primer for physicians. J Gen Intern Med. 2011;26:546-50.

11. Robinson P, Choi H, Do R, Merriman TR. Insight into rheumatological cause and effect through the use of Mendelian randomization. Nat Rev Rheumatol. 2016;12:486-96.

12. Wallace SL, Robinson H, Masi AT, Decker JL, McCarty DJ, Yu TF. Preliminary criteria for the classification of the acute arthritis of primary gout. Arthr Rheum. 1977;20:895-900.

13. Taylor HA Jr. The Jackson Heart Study: an overview. Ethn Dis. 2005;15:S6-1-3.

14. Burt VL, Harris T. The Third National Health and Nutrition Examination Survey: contributing data on aging and health. Gerontologist. 1994;34:486-90.

15. Team RC. R: a language and environment for statistical computing. Vienna: R Foundation for Statistical Computing; 2016.

16. Kell DB, Pretorius E. Serum ferritin is an important inflammatory disease marker, as it is mainly a leakage product from damaged cells. Metallomics. 2014;6:748-73.

17. Ruggiero C, Cherubini A, Ble A, Bos AJ, Maggio M, Dixit VD, et al. Uric acid and inflammatory markers. Eur Heart J. 2006;27:1174-81. 
18. Roseff R, Wohlgethan J, Sipe J, Canoso JJ. The acute phase response in gout. J Rheumatol. 1987;14:974-7.

19. Bolann BJ, Ulvik R. Release of iron from ferritin by xanthine oxidase. Role of the superoxide radical. Biochem J. 1987:243:55-9.

20. Benyamin B, Tonu E, Ried JS, Radhakrishnan A, Vermeulen SH, Traglia M, et al. Novel loci affecting iron homeostasis and their effects in individuals at risk for hemochromatosis. Nat Commun. 2014;5:4926.

21. Köttgen A, Albrecht E, Teumer A, Vitart V, Krumsiek J, Hundertmark C, et al. Genome-wide association analyses identify 18 new loci associated with serum urate concentrations. Nat Genet. 2013;45:145-54.

22. Burgess $\mathrm{S}$, Butterworth $\mathrm{A}$, Thompson SG. Mendelian randomization analysis with multiple genetic variants using summarized data. Genet Epidemiol. 2013;37:658-65

23. Hemani G, Zheng J, Wade KH, Laurin C, Elsworth B, Burgess S, et al. MR-Base: a platform for systematic causal inference across the phenome using billions of genetic associations, bioRxiv; 2016. p. 078972.

24. Lawlor DA, Harbord RM, Sterne JA, Timpson N, Davey Smith G. Mendelian randomization: using genes as instruments for making causal inferences in epidemiology. Stat Med. 2008;27:1133-63.

25. Burgess S, Small DS, Thompson SG. A review of instrumental variable estimators for Mendelian randomization. Stat Methods Med Res. 2015;26:2333-55.

26. Burgess S. Identifying the odds ratio estimated by a two-stage instrumental variable analysis with a logistic regression model. Stat Med. 2013;32:4726-47.

27. Didelez V, Meng S, Sheehan NA. Assumptions of IV methods for observational epidemiology. Stat Sci. 2010;25:22-40.

28. Bowden J, Smith GD, Burgess S. Mendelian randomization with invalid instruments: effect estimation and bias detection through egger regression. Int J Epidemiol. 2015;44:512-25.

29. Corbin LJ, Richmond RC, Wade KH, Burgess S, Bowden J, Davey Smith G, Timpson NJ. Body mass index as a modifiable risk factor for type 2 diabetes: refining and understanding causal estimates using Mendelian randomisation. Diabetes. 2016;65:3002-7.

30. Burgess S. Sample size and power calculations in Mendelian randomization with a single instrumental variable and a binary outcome. Int J Epidemiol. 2014:43:922-9

31. Burgess S, Davies NM, Thompson SG. Bias due to participant overlap in two-sample Mendelian randomization. Genet Epidemiol. 2016;40:597-608,

32. Sivera F, Andrés M, Pascual E. Serum uric acid drops during acute inflammatory episodes. Ann Rheum Dis. 2010;69(Suppl 3):122.

33. Aust SD, Morehouse LA, Thomas CE. Role of metals in oxygen radical reactions. J Free Radic Biol Med. 1985;1:3-25.

34. Howell RR, Wyngaarden JB. On the mechanism of peroxidation of uric acids by hemoproteins. J Biol Chem. 1960;235:3544-50.

35. Kellogg EW, Fridovich I. Liposome oxidation and erythrocyte lysis by enzymically generated superoxide and hydrogen peroxide. J Biol Chem. 1977:252:6721-8

36. Ames BN, Cathcart R, Schwiers E, Hochstein P. Uric acid provides an antioxidant defense in humans against oxidant-and radical-caused aging and cancer: a hypothesis. Proc Natl Acad Sci U S A. 1981;78:6858-62.

37. Davies K, Sevanian A, Muakkassah-Kelly S, Hochstein P. Uric acid-iron ion complexes. A new aspect of the antioxidant functions of uric acid. Biochem J. 1986;235:747-54

38. Stonehuerner J, Ghio AJ, Kennedy TP, Skinner KA. Elevations in xanthine oxidase $(\mathrm{XO})$ activity after silica exposure corresponds to complexed iron concentrations. Am J Respir Crit Care Med. 1998;157:A232.

39. Martelin E, Lapatto R, Raivio KO. Regulation of xanthine oxidoreductase by intracellular iron. Am J Physiol Cell Physiol. 2002;283:C1722-8.

40. del Greco F, Foco L, Pichler I, Eller P, Eller K, Benyamin B, et al. Serum iron level and kidney function: a Mendelian randomization study. Nephrol Dial Transplant. 2017;32:273-8.

41. Muntane J, Puig-Parellada P, Fernandez Y, Mitjavila S, Mitjavila MT. Antioxidant defenses and its modulation by iron in carrageenan-induced inflammation in rats. Clin Chim Acta. 1993;214:185-93.

42. Ward V, McGinty J, Church W. Iron (III) chloride injection increases nigral uric acid in Guinea-pig. Neuroreport. 1993:4:787-90.

43. Livrea M, Tesoriere L, Pintaudi A, Calabrese A, Maggio A, Freisleben HJ, et al. Oxidative stress and antioxidant status in beta-thalassemia major: iron overload and depletion of lipid-soluble antioxidants. Blood. 1996;88:3608-14.

44. Muirden K, Senator G. Iron in the synovial membrane in rheumatoid arthritis and other joint diseases. Ann Rheum Dis. 1968;27:38-48.
45. Blake DR, Hall ND, Bacon P, Dieppe PA, Halliwell B, Gutteridge JM. Effect of a specific iron chelating agent on animal models of inflammation. Ann Rheum Dis. 1983;42:89-93.

46. Andrews F, Morris C, Kondratowicz G, Blake DR. Effect of iron chelation on inflammatory joint disease. Ann Rheum Dis. 1987;46:327-33.

47. Flynn TJ, Cadzow M, Dalbeth N, Jones PB, Stamp LK, Harre Hindmarsh J, et al. Positive association of tomato consumption with serum urate: support for tomato consumption as an anecdotal trigger of gout flares. BMC Musculoskelet Disord. 2015:16:196.

48. Williams PT. Effects of diet, physical activity and performance, and body weight on incident gout in ostensibly healthy, vigorously active men. Am J Clin Nutr. 2008;87:1480-7.

49. Choi HK, Atkinson K, Karlson EW, Willett W, Curhan G. Purine-rich foods, dairy and protein intake, and the risk of gout in men. N Engl J Med. 2004; 350:1093-103.

50. Öztürk MA, Kaya A, Şenel S, Dönmez S, Cobankara V, Erhan C, et al. Demographic and clinical features of gout patients in Turkey: a multicenter study. Rheumatol Int. 2013;33:847-52.

51. Choi HK, Liu S, Curhan G. Intake of purine-rich foods, protein, and dairy products and relationship to serum levels of uric acid: the Third National Health and Nutrition Examination Survey. Arthr Rheum. 2005;52:283-9

52. Powell L, Emmerson B. Haemosiderosis associated with xanthine oxidase inhibition. Lancet. 1966;287:239-40

53. Emmerson B. Effects of allopurinol on iron metabolism in man. Ann Rheum Dis. 1966;25:700-3.

54. Powell LW. Changing concepts in haemochromatosis. Postgrad Med J. 1970:46:200-9

55. Gaffo AL, Schumacher HR, Saag KG, Taylor WJ, Dinella J, Outman R, et al. Developing a provisional definition of flare in patients with established gout. Arthritis Rheum. 2012;64:1508-17.
Ready to submit your research? Choose BMC and benefit from:

- fast, convenient online submission

- thorough peer review by experienced researchers in your field

- rapid publication on acceptance

- support for research data, including large and complex data types

- gold Open Access which fosters wider collaboration and increased citations

- maximum visibility for your research: over $100 \mathrm{M}$ website views per year

At $\mathrm{BMC}$, research is always in progress.

Learn more biomedcentral.com/submissions 